\title{
1 Effect of sunlight on the efficacy of commercial antibiotics used in agriculture
}

2 Sebastian Khan, Amanda Osborn, and Prahathees J. Eswara*

3 Department of Cell Biology, Microbiology, and Molecular Biology, University of South Florida,

4 Tampa, Florida, USA

$5 \quad$ *Address correspondence to Prahathees J. Eswara, eswara@usf.edu.

6 Keywords: Antibiotic stewardship, antibiotic resistance, Liberibacter; huanglongbing, Erwinia,

7 fire blight, aquaculture, streptomycin; oxytetracycline.

8 Running title: Effect of sunlight on commercial antibiotics

\section{ABSTRACT}

12 Antibiotic stewardship is of paramount importance to limit the emergence of antibiotic-

13 resistant bacteria in not only hospital settings, but also in animal husbandry,

14 aquaculture, and agricultural sectors. Currently, large quantities of antibiotics are

15 applied to treat agricultural diseases like citrus greening disease (CGD). The two

16 commonly used antibiotics approved for this purpose are streptomycin and

17 oxytetracycline. Although investigations are ongoing to understand how efficient this

18 process is to control the spread of CGD, to our knowledge, there have been no studies

19 that evaluate the effect of environmental factors such as sunlight on the efficacy of the

20 above-mentioned antibiotics. We conducted a simple disc-diffusion assay to study the

21 efficacy of streptomycin and oxytetracycline after exposure to sunlight for 7- or 14-day

22 periods using Escherichia coli and Bacillus subtilis as the representative strains of

23 Gram-negative and Gram-positive organisms respectively. Freshly prepared discs and

24 discs stored in the dark for 7 or 14 days served as our controls. We show that the 
25 antibiotic potential of oxytetracycline exposed to sunlight dramatically decreases over

26 the course of 14 days against both E. coli and B. subtilis. However, the effectiveness of

27 streptomycin was only moderately impacted by sunlight. It is important to note that

28 antibiotics that last longer in the environment may play a deleterious role in the rise and

29 spread of antibiotic-resistant bacteria. Further studies are needed to substantively

30 analyze the safety and efficacy of antibiotics used for broader environmental

31 applications.

\section{IMPORTANCE}

34 Although antibiotics have been used for agricultural purposes for decades, due to the 35 rapid rise in antibiotic resistance this usage needs to be revisited. Questions remain on 36 the appropriate mode of application of antibiotics and the actual benefits of using

37 antibiotics for treating the infections caused by plant pathogens, especially for the ones

38 that are intracellular in nature. Here we show that the two commonly used commercial

39 antibiotics, oxytetracycline and streptomycin, lose their efficacy at different rates in the

40 presence of sunlight. While the former loses its potency within days the latter remains

41 active for many days. Thus, oxytetracycline may not be active long enough to produce

42 desired effect and streptomycin may persist in the environment and as a side effect due

43 to its selective pressure, may force the rise of streptomycin-resistant pathogens.

\section{INTRODUCTION}

46 Antibiotic resistance-related mortalities are expected to exceed the other leading causes

47 of death such as cancer worldwide by 2050 [1]. Antibiotic stewardship is therefore 
48 promoted in all sectors including human health, animal husbandry, and agriculture [2-4].

49 The World Health Organization and the United States Centers for Disease Control and

50 Prevention have recognized antimicrobial resistance as an enormous ongoing threat to

51 public health [ㅌ, 6]. Runoff of antibiotics in hospital waste water [7] and intentional use in

52 aquaculture [8], animal husbandry [9-11], and crop management [12] contribute to the

53 rise and spread of antibiotic resistant bacteria. In this context, alarm was raised recently

54 regarding the spraying of antibiotics in open fields as an infection control strategy to

55 stem the spread of bacterial disease in plants [13, 14]. Specifically, the strategy

56 approved by the United States Environmental Protection Agency [13, 15, 16] is to use

57 streptomycin and oxytetracycline to control the spread of citrus greening disease

58 (CGD), also known as huanglongbing (yellow dragon disease). CGD is a devastating

59 bacterial disease caused by Candidatus Liberibacter asiaticus (CLas) that is transmitted

60 between plants by certain psyllids, which are sap-feeding insects. CLas is a fastidious,

61 Gram-negative, intracellular plant pathogen that belongs to the phylum of $\alpha-$

62 proteobacteria [17, 18]. Streptomycin and oxytetracycline are also used to treat

63 infections caused by another bacterial plant pathogen, Erwinia amylovora, which causes

64 fire blight in apples, pears, and other related species [19]. E. amylovora has dual growth

65 modes - an epiphytic mode that is readily accessible for external antibiotics and an

66 endophytic mode that is less accessible to external antibiotics [19]. In addition,

67 tetracycline antibiotics including oxytetracycline are used in animal husbandry [20] and

68 aquaculture [21]. Apart from the uses described above, data also suggests that

69 antibiotics may find their way into and possibly persist in different animal and plant

70 tissues [22-25], which could be an alternate pathway that can lead to the development of 
71 antibiotic-resistant bacteria. Thus, a comprehensive knowledge of the fate of antibiotics

72 used in agriculture is urgently needed to hopefully curb the rise and spread of antibiotic

73 resistance.

75 Although the application of antibiotics to treat CGD inspired us to pursue this study, the

76 primary objective of this report is to investigate the effect of environmental factors,

77 specifically sunlight, on streptomycin and oxytetracycline. To this end, we conducted a

78 disc-diffusion assay with Gram-negative Escherichia coli and Gram-positive Bacillus

79 subtilis and monitored the zones of inhibition of antibiotic-containing discs that were

80 exposed to sunlight for a 7- or 14-day period. Discs that were kept in the dark for

81 equivalent duration or that were freshly prepared served as our controls. Based on our

82 results, we report that sunlight significantly impairs the efficacy of oxytetracycline, but

83 only moderately impacts streptomycin. While short-lived antibiotics may not be active

84 long enough for their intended purpose, stable antibiotics may apply constant selection

85 pressure and create an environment conducive for the emergence of antibiotic-resistant

86 strains [26]. Although this study (designed for undergraduate-level students [27]) is not

87 comprehensive, our data provides a window into the life span of commercial antibiotics

88 in nature that we hope highlights the need for further rigorous safety and efficacy

89 investigations for the environmental use of antibiotics.

90

91

92 


\section{RESULTS}

\section{Oxytetracycline loses its antibiotic potential in the presence of sunlight in the}

\section{6 span of few days.}

97 To monitor the effect of sunlight on the efficacy of oxytetracycline, we conducted a disc-

98 diffusion assay. Briefly, we prepared multiple discs with oxytetracycline (50 $\mu \mathrm{g})$

99 dissolved in water and placed the antibiotic-laden discs in either a natural outdoor

100 setting with abundant sunlight to simulate agricultural use, or in a dark indoor cabinet for

1017 or 14 days. In addition to the discs that were kept in the dark, we also used freshly

102 prepared discs and vehicle (water) discs as controls. The discs were then placed, as

103 shown in Fig. 1, on a pre-inoculated plate containing either a lawn of $E$. coli or $B$.

104 subtilis cells. In all cases, as expected, the blank disc ( $\mathrm{N}$; negative control) and the

105 freshly prepared discs ( $\mathrm{P}$; positive control) showed negligible and maximum zones of

106 inhibition (ZOI), respectively (Figs. 1A-D). The discs that were kept in the dark (labeled

107 "D") for the duration of 7 or 14 days appeared to produce similar ZOI as our positive

108 control of approximately $9 \mathrm{~mm}$ for $E$. coli and $8 \mathrm{~mm}$ for $B$. subtilis (Figs. 1EF). This

109 suggests that oxytetracycline maintains its efficiency in the dark at room temperature for

110 at least the maximum duration of this experiment (14 days). Next, we quantified the ZOI

111 of the discs that were exposed to sunlight (labeled "L") for either a 7- or 14-day period.

112 We observed that the efficacy of oxytetracycline gradually and significantly decreased

113 over time to almost similar to our negative control in both $E$. coli and $B$. subtilis and only

114 retained less than $15 \%$ activity after 14 days (Figs. 1A-F). This implies that in the

115 presence of sunlight, oxytetracycline loses its antibiotic potential in a matter of few days. 


\section{Moderate negative effects of sunlight on the efficacy of streptomycin.}

118 A similar experimental setup to the one discussed above was adopted for studying the

119 effects of sunlight on streptomycin. As noted earlier, blank discs and freshly prepared

120 discs with streptomycin $(200 \mu \mathrm{g})$ served as our negative and positive controls

121 respectively. As expected, the ZOI were unobservable for our blank discs and at a

122 maximum for our positive controls (Figs. 1G-L). Similar to oxytetracycline, streptomycin

123 is also able to maintain its efficacy when kept in darkness for the duration of our

124 experiment (Figs. 1G-L). However, unlike oxytetracycline, streptomycin appears to be

125 moderately resistant to sunlight. At the 7-day mark, based on the ZOI (Figs. 1KL), the

126 discs exposed to sunlight appear to have retained almost approximately $80 \%$ and $70 \%$

127 of their activity in E.coli and B. subtilis respectively, when compared to that of our

128 positive control. Further measurable decrease to nearly $50 \%$ efficiency compared to our

129 positive control was noted subsequent to 14 days of sunlight exposure for $E$. coli.

130 However, the decrease in efficiency for $B$. subtilis at the 14-day time point was within

131 the standard error when compared to that of the 7-day time point (Figs. 1HJKL).

\section{DISCUSSION}

135 Rapid rise of antibiotic resistance in bacteria is a major concern worldwide with

136 enormous predicted fatalities. Antibiotics are now routinely used in clinics, animal

137 husbandry, and agriculture. Acknowledgement of the fact that the rise of antibiotic

138 resistance stemming from one of those settings could potentially render antibiotics

139 useless and lead to the formation of a multidisciplinary collaborative initiative under the 
140 umbrella term One Health [2, 3]. Despite this, environmental antibiotic pollution is a

141 growing concern that requires urgent attention [28].

143 Some commercial antibiotics such as oxytetracycline and streptomycin are produced by

144 soil-dwelling Streptomyces spp. However, soil bacteria do not produce antibiotics at

145 levels comparable to commercial applications - which can occasionally be in the scale

146 of thousands of kilograms $[\underline{13}, \underline{15}, \underline{16}$. Also, the efficiency of superficial application of

147 antibiotics in limiting the growth of plant bacterial pathogens, including some that are

148 intracellular, is unclear. Recent studies have suggested injection of oxytetracycline

149 produces better results [19, 29]. The spread of antibiotic resistance has been

150 documented from agricultural use for antibiotics like tetracycline and streptomycin [30-

$15132]$. It has been noted that antibiotic resistance genes are naturally found in the

152 environment [33, 34]. Therefore, application of consistent selection pressure by

153 excessive and frequent use of antibiotics may enrich the population of naturally resistant

154 organisms. However, at least in some instances under certain conditions, it was noted

155 that streptomycin use did not alter the composition of soil microbial communities

156 appreciably [35, $\underline{36}]$.

158 Several reports on degradation kinetics and mechanisms of degradation of the

159 antibiotics that are discussed here are available [21, 37-44]. It has been reported that the

160 half-life of oxytetracycline at $25^{\circ} \mathrm{C}$ is approximately 7 days, at $35^{\circ} \mathrm{C}$ is 3 days and at 60

$161{ }^{\circ} \mathrm{C}$ is 0.2 day, indicating a rapid temperature-dependent degradation of oxytetracycline,

162 as the half-life at $4^{\circ} \mathrm{C}$ is 120 days [37]. According to the same study, the half-life due to 
163 photolysis in the presence of sunlight is in the same order of magnitude. A similar

164 investigation exists evaluating the photostability and temperature stability of

165 streptomycin [44]. Briefly, the photodegradation of streptomycin is more modest than

166 oxytetracycline by nearly 10 -fold. The half-life of streptomycin was determined to be

167 nearly 105,42 and 30 days at $15^{\circ} \mathrm{C}, 25^{\circ} \mathrm{C}$, and $40^{\circ} \mathrm{C}$ respectively, implying a

168 decreased rate of degradation when compared to oxytetracycline. A description of the

169 possible degradation products of oxytetracycline and streptomycin are available [37, 44].

170 Our results showing a faster loss of efficacy for oxytetracycline than streptomycin upon

171 sunlight exposure are therefore in agreement with the reported degradation kinetics of

172 these antibiotics. To our knowledge, analysis such as the one we have conducted to

173 monitor the biological efficacy of antibiotics subsequent to exposure to environmental

174 elements are either lacking or not publicly available (as recognized by this article [14]).

175 Our experimental conditions simulate the agricultural use of antibiotics and our results

176 indicate that sunlight (heat and/or ultraviolet radiation) contributes to the degradation of

177 oxytetracycline and streptomycin. Although our report is limited in scope, we believe it

178 sheds light on the fate of antibiotics in the environment. Further studies to understand

179 the effects of antibiotics are needed to inform the public and appropriate regulatory

180 agencies [2-4]. 


\section{MATERIALS AND METHODS}

\section{Strains used and general methods}

188 The $B$. subtilis strain PY79 and the E. coli strain K-12 were incubated in 2 ml LB at 37

$189{ }^{\circ} \mathrm{C}$ and grown until the culture OD600 reached 1.0 (exponential growth phase). A $100 \mu \mathrm{l}$

190 aliquot of culture was then spread onto LB agar plates using sterile beads and set to dry

191 completely prior to the placement of discs, see section below.

\section{Disc-diffusion assay}

194 UV sterilized Whatman filter paper discs $(7 \mathrm{~mm})$ were impregnated with $5 \mu$ of a freshly

195 made stock antibiotic solution of either $40 \mathrm{mg} / \mathrm{ml}$ streptomycin sulfate (MilliporeSigma)

196 in sterile distilled water or $10 \mathrm{mg} / \mathrm{ml}$ oxytetracycline hydrochloride (Alfa Aesar) in sterile

197 distilled water to reach a concentration of $200 \mu \mathrm{g}$ for streptomycin and $50 \mu \mathrm{g}$ for

198 oxytetracycline in each disc, and then set to dry completely. The concentrations

199 selected were based on the concentration range recommended for agricultural use [45],

200 and after empirically ensuring similar initial zones of inhibition for both antibiotics in the

201 strains tested. To mimic the use of agricultural antibiotics, the discs were then placed

202 outdoors (during spring months in Tampa, FL, USA where the average daytime

203 temperature ranged from 27 to $32{ }^{\circ} \mathrm{C}$ ) in direct sunlight for 7 or 14 consecutive 24-h

204 periods (days) in parafilm-sealed sterile Petri dishes. Discs that were kept indoors in a

205 dark cabinet at room temperature for 7 or 14 days, freshly prepared discs made the day

206 of testing, and $5 \mu \mathrm{l}$ of sterile water were used as controls. Discs were then transferred

207 and pressed onto the pre-inoculated LB agar plates and incubated overnight at $37^{\circ} \mathrm{C}$. 
208 The zone of inhibition measurements were taken from the center of the disc to the edge

209 of the zone of inhibition, minus disc radius $(3.5 \mathrm{~mm})$.

210

\section{Statistical analysis}

212 GraphPad Prism Software (version 8.3.1) was used to analyze the data. All data

213 represent biological triplicate data with technical replicates. Graphs show mean values

214 and error bars represent standard deviation (SD).

\section{ACKNOWLEDGEMENTS}

218 We thank our lab members for comments on the manuscript and assistance with data

219 visualization. This work was funded by a start-up grant from USF (PE). A preprint of this 220 manuscript is available on bioRxiv [46].

\section{AUTHOR CONTRIBUTIONS}

224 The conception and design of the study (SK, PE), data acquisition (SK, AO), analysis

225 and/or interpretation of the data (SK, AO, PE), and writing of the manuscript (SK, PE). 


\section{FIGURE LEGEND}

\section{Figure 1. Oxytetracycline and streptomycin lose antibiotic potential in the}

233 presence of sunlight. Shown are representative disc-diffusion assay results for the

234 effects of oxytetracycline (A-D) or streptomycin (G-J) on growth of either Gram-positive

235 B. subtilis or Gram-negative E. coli. Quantification of the zones of inhibition in

236 millimeters are plotted for each 7- or 14-day cohort of oxytetracycline (E-F) and

237 streptomycin (K-L). Significance was determined using a one-way ANOVA with Tukey's

238 multiple comparisons analysis. Error bars represent standard deviation (SD) of the

239 mean from three biological replicates. N: negative control (discs prepared with sterile

240 water), P: positive control (discs prepared the day of testing), L7 or L14: 7 or 14 days in

241 sunlight, D7 or D14: 7 or 14 days in darkness. ${ }^{* * *}: p<0.0001,{ }^{* * *}: p<0.001,{ }^{* *}: p<0.01$.

244 REFERENCES

245 1. Editors PM. Antimicrobial Resistance: Is the World UNprepared? PLoS Med.

246 2016;13(9):e1002130. doi: 10.1371/journal.pmed.1002130. PubMed PMID: 27618631;

247 PubMed Central PMCID: PMCPMC5019402.

248 2. McEwen SA, Collignon PJ. Antimicrobial Resistance: a One Health Perspective.

249 Microbiol Spectr. 2018;6(2). doi: 10.1128/microbiolspec.ARBA-0009-2017. PubMed

250 PMID: 29600770.

251 3. Hernando-Amado S, Coque TM, Baquero F, Martinez JL. Defining and

252 combating antibiotic resistance from One Health and Global Health perspectives. Nat 
253 Microbiol. 2019;4(9):1432-42. doi: 10.1038/s41564-019-0503-9. PubMed PMID:

25431439928.

255 4. Thanner S, Drissner D, Walsh F. Antimicrobial Resistance in Agriculture. mBio.

256 2016;7(2):e02227-15. doi: 10.1128/mBio.02227-15. PubMed PMID: 27094336; PubMed

257 Central PMCID: PMCPMC4850276.

258 5. Toner E, Adalja A, Gronvall GK, Cicero A, Inglesby TV. Antimicrobial resistance

259 is a global health emergency. Health Secur. 2015;13(3):153-5. doi:

260 10.1089/hs.2014.0088. PubMed PMID: 26042858; PubMed Central PMCID:

261 PMCPMC4486712.

262 6. Kadri SS. Key Takeaways From the U.S. CDC's 2019 Antibiotic Resistance

263 Threats Report for Frontline Providers. Crit Care Med. 2020;48(7):939-45. doi:

264 10.1097/CCM.0000000000004371. PubMed PMID: 32282351; PubMed Central PMCID:

265 PMCPMC7176261.

266 7. Hocquet D, Muller A, Bertrand X. What happens in hospitals does not stay in

267 hospitals: antibiotic-resistant bacteria in hospital wastewater systems. J Hosp Infect.

268 2016;93(4):395-402. doi: 10.1016/j.jhin.2016.01.010. PubMed PMID: 26944903.

269 8. Cabello FC, Godfrey HP, Buschmann AH, Dolz HJ. Aquaculture as yet another

270 environmental gateway to the development and globalisation of antimicrobial resistance.

271 Lancet Infect Dis. 2016;16(7):e127-e33. doi: 10.1016/S1473-3099(16)00100-6. PubMed

272 PMID: 27083976.

273 9. Martin MJ, Thottathil SE, Newman TB. Antibiotics Overuse in Animal Agriculture:

274 A Call to Action for Health Care Providers. Am J Public Health. 2015;105(12):2409-10. 
275 doi: 10.2105/AJPH.2015.302870. PubMed PMID: 26469675; PubMed Central PMCID:

276 PMCPMC4638249.

277 10. Landers TF, Cohen B, Wittum TE, Larson EL. A review of antibiotic use in food

278 animals: perspective, policy, and potential. Public Health Rep. 2012;127(1):4-22. doi:

279 10.1177/003335491212700103. PubMed PMID: 22298919; PubMed Central PMCID:

280 PMCPMC3234384.

281 11. Van Boeckel TP, Pires J, Silvester R, Zhao C, Song J, Criscuolo NG, et al.

282 Global trends in antimicrobial resistance in animals in low- and middle-income

283 countries. Science. 2019;365(6459). doi: 10.1126/science.aaw1944. PubMed PMID:

28431604207.

285 12. Sundin GW, Wang N. Antibiotic Resistance in Plant-Pathogenic Bacteria. Annu

286 Rev Phytopathol. 2018;56:161-80. doi: 10.1146/annurev-phyto-080417-045946.

287 PubMed PMID: 29856934.

288 13. McKenna M. Antibiotics set to flood Florida's troubled orange orchards. Nature.

289 2019;567(7748):302-3. doi: 10.1038/d41586-019-00878-4. PubMed PMID: 30890811.

290 14. Editorial. Spraying diseased citrus orchards with antibiotics could backfire.

291 Nature. 2019;567(7748):283. doi: 10.1038/d41586-019-00875-7. PubMed PMID:

29230890810.

293 15. Collins S, Kough JL. Review of GeoLogic/Agrosource's Analysis of

294 Oxytetracycline's Safety with Regard to Its Microbiological Effect on Bacteria of Human 295 Health Concern (FDA/CVM Guidance to Industry \#152) for Registration on Citrus Crop

296 Group 10-10 [Memorandum] Washington, D.C. US Environmental Protection Agency.

297 2017; https://www.regulations.gov/document?D=EPA-HQ-OPP-2015-0820-0012. 
298 16. Donley N. The USA lags behind other agricultural nations in banning harmful 299 pesticides. Environ Health. 2019;18(1):44. doi: 10.1186/s12940-019-0488-0. PubMed

300 PMID: 31170989; PubMed Central PMCID: PMCPMC6555703.

301 17. Achor D, Welker S, Ben-Mahmoud S, Wang C, Folimonova SY, Dutt M, et al. 302 Dynamics of Candidatus Liberibacter asiaticus Movement and Sieve-Pore Plugging in 303 Citrus Sink Cells. Plant Physiol. 2020;182(2):882-91. doi: 10.1104/pp.19.01391.

304 PubMed PMID: 31818905; PubMed Central PMCID: PMCPMC6997701.

305 18. Merfa MV, Perez-Lopez E, Naranjo E, Jain M, Gabriel DW, De La Fuente L.

306 Progress and Obstacles in Culturing 'Candidatus Liberibacter asiaticus', the Bacterium 307 Associated with Huanglongbing. Phytopathology. 2019;109(7):1092-101. doi:

308 10.1094/PHYTO-02-19-0051-RVW. PubMed PMID: 30998129.

309 19. Acimovic SG, Zeng Q, McGhee GC, Sundin GW, Wise JC. Control of fire blight

310 (Erwinia amylovora) on apple trees with trunk-injected plant resistance inducers and

311 antibiotics and assessment of induction of pathogenesis-related protein genes. Front

312 Plant Sci. 2015;6:16. doi: 10.3389/fpls.2015.00016. PubMed PMID: 25717330; PubMed

313 Central PMCID: PMCPMC4323746.

314 20. Granados-Chinchilla F, Rodriguez C. Tetracyclines in Food and Feedingstuffs:

315 From Regulation to Analytical Methods, Bacterial Resistance, and Environmental and

316 Health Implications. J Anal Methods Chem. 2017;2017:1315497. doi:

317 10.1155/2017/1315497. PubMed PMID: 28168081; PubMed Central PMCID: 

quality during and after its administration, environmental fate, toxicity and bacterial

321 resistance. Reviews in Aquaculture. 2019;11(4):1176-94. doi: 10.1111/raq.12286.

322 22. Mayerhofer G, Schwaiger-Nemirova I, Kuhn T, Girsch L, Allerberger F. Detecting

323 streptomycin in apples from orchards treated for fire blight. J Antimicrob Chemother.

324 2009;63(5):1076-7. doi: 10.1093/jac/dkp055. PubMed PMID: 19240075.

325 23. Araby E, Nada HG, Abou El-Nour SA, Hammad A. Detection of tetracycline and

326 streptomycin in beef tissues using Charm II, isolation of relevant resistant bacteria and

327 control their resistance by gamma radiation. BMC Microbiol. 2020;20(1):186. doi:

328 10.1186/s12866-020-01868-7. PubMed PMID: 32600267; PubMed Central PMCID:

329 PMCPMC7325294.

330 24. Poapolathep A, Poapolathep S, Jermnak U, Imsilp K, Wannapat N, Sugita-

331 Konishi $\mathrm{Y}$, et al. Muscle tissue kinetics of oxytetracycline following intramuscular and

332 oral administration at two dosages to giant freshwater shrimp (Macrobrachium

333 rosenbergii). J Vet Pharmacol Ther. 2008;31(6):517-22. doi: 10.1111/j.1365-

334 2885.2008.00988.x. PubMed PMID: 19000273.

335 25. Al-Rimawi F, Hijaz F, Nehela Y, Batuman O, Killiny N. Uptake, Translocation, 336 and Stability of Oxytetracycline and Streptomycin in Citrus Plants. Antibiotics (Basel).

337 2019;8(4). doi: 10.3390/antibiotics8040196. PubMed PMID: 31717884; PubMed Central 338 PMCID: PMCPMC6963747.

339 26. Shentu JL, Zhang K, Shen DS, Wang MZ, Feng HJ. Effect from low-level 340 exposure of oxytetracycline on abundance of tetracycline resistance genes in arable 
341 soils. Environ Sci Pollut Res Int. 2015;22(17):13102-10. doi: 10.1007/s11356-015-4099-

342 1. PubMed PMID: 25925140.

343 27. Li J, Luo L. Nurturing Undergraduate Researchers in Biomedical Sciences. Cell.

$344 \quad 2020 ; 182(1): 1-4$

345 28. Kraemer SA, Ramachandran A, Perron GG. Antibiotic Pollution in the

346 Environment: From Microbial Ecology to Public Policy. Microorganisms. 2019;7(6). doi:

347 10.3390/microorganisms7060180. PubMed PMID: 31234491; PubMed Central PMCID:

348 PMCPMC6616856.

349 29. Li J, Pang Z, Duan S, Lee D, Kolbasov VG, Wang N. The in Planta Effective

350 Concentration of Oxytetracycline Against 'Candidatus Liberibacter asiaticus' for

351 Suppression of Citrus Huanglongbing. Phytopathology. 2019;109(12):2046-54. doi:

352 10.1094/PHYTO-06-19-0198-R. PubMed PMID: 31369360.

353 30. Cycon M, Mrozik A, Piotrowska-Seget Z. Antibiotics in the Soil Environment-

354 Degradation and Their Impact on Microbial Activity and Diversity. Front Microbiol.

355 2019;10:338. doi: 10.3389/fmicb.2019.00338. PubMed PMID: 30906284; PubMed

356 Central PMCID: PMCPMC6418018.

357 31. Tancos KA, Villani S, Kuehne S, Borejsza-Wysocka E, Breth D, Carol J, et al.

358 Prevalence of Streptomycin-Resistant Erwinia amylovora in New York Apple Orchards.

359 Plant Dis. 2016;100(4):802-9. doi: 10.1094/PDIS-09-15-0960-RE. PubMed PMID:

36030688602.

361 32. Popowska M, Rzeczycka M, Miernik A, Krawczyk-Balska A, Walsh F, Duffy B.

362 Influence of soil use on prevalence of tetracycline, streptomycin, and erythromycin

363 resistance and associated resistance genes. Antimicrob Agents Chemother. 

Central PMCID: PMCPMC3294877.

33. Sundin GW, Monks DE, Bender CL. Distribution of the streptomycin-resistance

367 transposon Tn5393 among phylloplane and soil bacteria from managed agricultural habitats. Can J Microbiol. 1995;41(9):792-9. doi: 10.1139/m95-109. PubMed PMID:

7585356.

370 34. Schmitt H, Stoob K, Hamscher G, Smit E, Seinen W. Tetracyclines and

371 tetracycline resistance in agricultural soils: microcosm and field studies. Microb Ecol.

372 2006;51(3):267-76. doi: 10.1007/s00248-006-9035-y. PubMed PMID: 16598633.

373 35. Walsh F, Smith DP, Owens SM, Duffy B, Frey JE. Restricted streptomycin use in

374 apple orchards did not adversely alter the soil bacteria communities. Front Microbiol.

375 2013;4:383. doi: 10.3389/fmicb.2013.00383. PubMed PMID: 24550889; PubMed

376 Central PMCID: PMCPMC3908321.

377 36. Shade A, Klimowicz AK, Spear RN, Linske M, Donato JJ, Hogan CS, et al.

378 Streptomycin application has no detectable effect on bacterial community structure in

379 apple orchard soil. Appl Environ Microbiol. 2013;79(21):6617-25. doi:

380 10.1128/AEM.02017-13. PubMed PMID: 23974143; PubMed Central PMCID:

381 PMCPMC3811482.

382 37. Xuan R, Arisi L, Wang Q, Yates SR, Biswas KC. Hydrolysis and photolysis of

383 oxytetracycline in aqueous solution. J Environ Sci Health B. 2010;45(1):73-81. doi:

384 10.1080/03601230903404556. PubMed PMID: 20390934.

385 38. Choi S, Sim W, Jang D, Yoon Y, Ryu J, Oh J, et al. Antibiotics in coastal

386 aquaculture waters: Occurrence and elimination efficiency in oxidative water treatment 
processes. J Hazard Mater. 2020;396:122585. doi: 10.1016/j.jhazmat.2020.122585.

388

389

390

391

392

393

394

395

396

397

398

399

400

401

402

403

404

405

406

407

408

PubMed PMID: 32298861.

39. Wang $Q$, Yates SR. Laboratory study of oxytetracycline degradation kinetics in animal manure and soil. J Agric Food Chem. 2008;56(5):1683-8. doi:

10.1021/jf072927p. PubMed PMID: 18257526.

40. Liu Y, Bao Y, Cai Z, Zhang Z, Cao P, Li X, et al. The effect of aging on sequestration and bioaccessibility of oxytetracycline in soils. Environ Sci Pollut Res Int. 2015;22(14):10425-33. doi: 10.1007/s11356-015-4190-7. PubMed PMID: 25721525.

41. Slana M, Dolenc MS. Environmental Risk Assessment of antimicrobials applied in veterinary medicine-A field study and laboratory approach. Environ Toxicol Pharmacol. 2013;35(1):131-41. doi: 10.1016/j.etap.2012.11.017. PubMed PMID: 23274419.

42. Leal JF, Esteves VI, Santos EBH. Solar photodegradation of oxytetracycline in brackish aquaculture water: New insights about effects of $\mathrm{Ca} 2+$ and $\mathrm{Mg} 2+$. Journal of Photochemistry and Photobiology A: Chemistry. 2019;372:218-25.

43. Li Z-j, Qi W-n, Feng Y, Liu Y-w, Ebrahim S, Long J. Degradation mechanisms of oxytetracycline in the environment. Journal of Integrative Agriculture. 2019;18(9):195360.

44. Shen Y, Zhao W, Zhang C, Shan Y, Shi J. Degradation of streptomycin in aquatic environment: kinetics, pathway, and antibacterial activity analysis. Environ Sci Pollut Res Int. 2017;24(16):14337-45. Epub 2017/04/22. doi: 10.1007/s11356-017-8978-5. PubMed PMID: 28429270. 
409 45. Vidaver AK. Uses of antimicrobials in plant agriculture. Clin Infect Dis. 2002;34

410 Suppl 3:S107-10. Epub 2002/05/04. doi: 10.1086/340247. PubMed PMID: 11988880.

411 46. Khan S, Osborn A, Eswara PJ. Effect of sunlight on the efficacy of commercial

412 antibiotics used in agriculture. bioRxiv. 2020;197848. doi:

413 https://doi.org/10.1101/2020.07.10.197848. 
